\title{
Gimeracil, a component of S-1, may enhance the antitumor activity of X-ray irradiation in human cancer xenograft models in vivo
}

\author{
MASAKAZU FUKUSHIMA ${ }^{1}$, KAZUKI SAKAMOTO ${ }^{1}$, MINORU SAKATA ${ }^{1}$, \\ FUMIO NAKAGAWA ${ }^{1}$, HITOSHI SAITO ${ }^{1}$ and YU SAKATA $^{2}$ \\ ${ }^{1}$ Tokushima Research Center, Taiho Pharmaceutical Co., Ltd., 224-2 Hiraishi-ebisuno, Kawauchi, Tokushima 771-0194; \\ ${ }^{2}$ Misawa Municipal Hospital, 4-1-10 Chuo-cho, Misawa 033-0001, Japan
}

Received April 20, 2010; Accepted July 6, 2010

DOI: $10.3892 /$ or_00000987

\begin{abstract}
Chemoradiotherapy is a useful treatment strategy in patients with locally advanced cancers. In particular, combination of 5-fluorouracil (5-FU) with X-ray irradiation is effective for the treatment of some types of gastrointestinal cancers. We investigated the antitumor effects of combination treatment with X-ray and S-1, a unique formulation of 5-FU, on human cancer xenografts in nude mice and compared the efficacy of this treatment to that of radiotherapy combined with cisplatin, UFT, another oral 5-FU prodrug, and intravenous 5-FU. Tumors implanted into the left hind legs of mice were treated with a dose of 2 or 5 Gy X-ray irradiation on days 1 and 8 , and S-1, UFT and 5-FU were administered for 14 days. The efficacy of combined treatment with 8.3 $\mathrm{mg} / \mathrm{kg} \mathrm{S}-1$ and 2 Gy X-ray irradiation in treating non-small cell lung cancer xenografts (Lu-99 and LC-11) was significantly higher than that of treatment with S-1 alone or 2 Gy X-ray irradiation alone, and the antitumor activity of combined treatment was similar to that of $5 \mathrm{~Gy} X$-ray irradiation alone. Although $8.3 \mathrm{mg} / \mathrm{kg} \mathrm{S}-1$ and $17.5 \mathrm{mg} / \mathrm{kg}$ UFT had equivalent antitumor activity; the antitumor efficacy of combination treatment with S-1 and 2 Gy X-ray irradiation on LC-11 tumors was significantly higher than that of combination treatment with UFT and 2 Gy X-ray irradiation. Combination treatment with S-1 and X-ray irradiation was also more effective against pancreatic tumors than combination treatment with intravenous 5-FU and X-ray irradiation. To elucidate the reason for the increased antitumor efficacy of combination treatment with S-1 and $\mathrm{X}$-ray irradiation, the antitumor effect of gimeracil, one of the components of S-1, was tested in combination with 2 Gy $\mathrm{X}$-ray irradiation. These experiments demonstrated that
\end{abstract}

Correspondence to: Dr Masakazu Fukushima, Tokushima Research Center, Taiho Pharmaceutical Co., Ltd., 224-2 Hiraishiebisuno, Kawauchi, Tokushima 771-0194, Japan

E-mail: fukusima@taiho.co.jp

Key words: S-1, 5-FU, gimeracil, X-ray, chemoradiotherapy, CDDP gimeracil enhanced the efficacy of X-ray irradiation against lung as well as head and neck cancer xenografts in a dosedependent manner. Furthermore, we observed decreased expression of $\gamma-\mathrm{H} 2 \mathrm{AX}$ protein, a marker of DNA repair, in LC-11 tumors treated with X-ray irradiation and gimeracil compared to that observed in tumors treated with X-ray irradiation alone, suggesting that gimeracil may inhibit rapid repair of X-ray-induced DNA damage in tumors. The present study suggests that chemoradiotherapy using S-1 acts through a novel mechanism and may prove useful in treating patients with locally advanced cancers whose disease progression is difficult to control using chemotherapy alone.

\section{Introduction}

Combination of radiotherapy with chemotherapy, also referred to as concurrent chemoradiotherapy, has become a standard strategic practice in the treatment of patients with locally advanced cancers including non-small cell lung, head and neck, oral cavity, and esophageal cancers. Currently, several cytotoxic drugs, including cisplatin (CDDP), 5-fluorouracil (5-FU) and gemcitabine (Gem), are frequently used in combination with fractionated radiation for the treatment of such cancers $(1,2)$.

Combination treatment with radiation and anticancer drugs are based on the different mechanisms of each anticancer agent, such as potentiating radiation-induced DNA damage, preventing repair of radiation-induced DNA damage, and arresting the cell cycle at the G2/M phase, the most radiosensitive phase in cancer cells, which are insensitive to radiation during S-phase (2-4). Furthermore, concurrent use of anticancer drugs seems to play an important role in inhibiting systemic micrometastasis of tumor cells, and combined treatment with radiation and anticancer drugs controls locally advanced tumors, leading to prolonged progression-free and/ or overall survival of patients (5-8).

5-FU, a typical antimetabolite that mainly inhibits DNA synthesis, is widely used to treat patients with breast, head and neck, and gastrointestinal (gastric, colorectal, esophageal, and pancreatic) cancers in combination with other cytotoxic drugs. Recently, it has been used with molecular targeting agents in metastatic or adjuvant settings; therefore, 5-FU- 
based regimens have been employed in radiation therapy (9-13).

Despite the widespread use of 5-FU, chemoradiotherapy with 5-FU has not been used to treat advanced non small-cell lung cancer (NSCLC) because 5-FU exhibits low antitumor efficacy and is not useful as an anticancer drug for treatment of NSCLC.

On the other hand, UFT (tegafur-uracil), an oral 5-FU prodrug, is available to treat NSCLC as adjuvant chemotherapy (14), and in concomitant combination with radiation, UFT has been demonstrated to improve the outcome of patients with locally advanced NSCLC (15).

To further improve the clinical response and reduce 5-FU-induced gastrointestinal (GI) events, we developed $\mathrm{S}-1$, a new oral 5-FU formulation. S-1 is composed of the 5-FU prodrug tegafur, gimeracil (5-chloro-2,4-dihydroxypyridine), which reversibly inhibits dihydropyrimidine dehydrogenase (DPD)-mediated inactivation of 5-FU in the liver and tumors, and potassium oteracil (potassium oxonate), an inhibitor of orotate phosphoribosyltransferase (OPRT) that protects against 5-FU-induced GI damage $(16,17)$. S-1 was found to be clinically effective against NSCLC and pancreatic, gastric, CRC, head and neck, and breast cancers (18-21).

Several reports have suggested that chemoradiotherapy using S-1 in combination with X-ray irradiation is fairly effective against various types of cancer xenografts, and its anticancer effects are mediated by mechanisms including induction of apoptosis, inhibition of survival signals or suppression of radiation-induced hypoxia-inducible factor-1 (HIF-1) activation (22-25). Preliminary clinical studies have demonstrated the potential efficacy of chemoradiotherapy with $\mathrm{S}-1$ and radiation in treating locally advanced head and neck and pancreatic cancers $(26,27)$.

Although chemoradiotherapy with $\mathrm{S}-1$ seems to be a useful treatment option for patients with locally advanced cancers, currently there is no report comparing the efficacy of combination treatment with $\mathrm{S}-1$ and radiation with that of standard chemoradiotherapy.

We compared the antitumor efficacy of chemoradiotherapy with S-1 to that of chemoradiotherapy with 5-FU and/or its prodrug against human cancer xenografts in vivo and found that radiotherapy combined with S-1 was more effective in treating these tumors than conventional chemoradiotherapy and that the increased antitumor efficacy of combination treatment with S-1 and X-ray irradiation is, in a part, mediated by gimeracil, a component of $\mathrm{S}-1$.

The present study reports the enhanced anticancer activity of concurrent chemoradiotherapy with S-1 and X-ray irradiation in comparison to chemoradiotherapy with other anti-cancer drugs and the possible mechanism by which gimeracil may contribute to radiosensitization in human tumor xenografts.

\section{Materials and methods}

Chemicals. 5-Fluorouracil (5-FU) and cisplatin (CDDP) were obtained from Wako Pure Chemicals, Ltd. (Tokyo, Japan). Tegafur (FT), gimeracil (5-chloro-2,4-dihydroxypyridine) and potassium oteracil (potassium oxonate) were products of Taiho Pharmaceutical Co. (Tokyo, Japan). S-1 is a combination of $1 \mathrm{M} \mathrm{FT}, 0.4 \mathrm{M}$ gimeracil and $1 \mathrm{M}$ potassium oteracil. For immuno-blot analysis of proteins, anti- $\gamma-\mathrm{H} 2 \mathrm{AX}$ monoclonal antibody was purchased from Santa Cruz Biochemicals Inc. (San Diego, CA, USA).

Animals and tumor xenografts. Five-week old Balb/c-nu/nu mice were purchased from CLEA Japan Inc. (Tokyo, Japan) and were fed a sterilized pellet diet and autoclaved water ad libitum. Mice were housed in laminar air flow units throughout the therapeutic experiments. All animal experiments were performed according to the institutional guidelines.

Human non-small cell lung cancer Lu-99 and LC-11, human head and neck cancer $\mathrm{KB} / \mathrm{C} 3$, and human pancreatic cancer PAN-4 cells were obtained from the Central Institute for Experimental Animals (Kawasaki, Japan).

Local tumor irradiation. Irradiation was performed with a small animal X-ray generator (MBR-1505R2, Hitachi Medical Corp., Tokyo, Japan). Un-anesthetized mice were immobilized on an X-ray-block box, and irradiation was delivered locally to the tumor implanted into the right behind leg while the rest of the body was shielded.

Antitumor experiments. Nude mice were divided into groups of six mice each. Lu-99, LC-11, KB/C3 and PAN-4 tumors were xenografted by s.c. implantation of $2-\mathrm{mm}^{3}$ fragments into the right behind leg of each mouse. After 7 days, S-1 $(8.3 \mathrm{mg} / \mathrm{kg})$, UFT $(17.5 \mathrm{mg} / \mathrm{kg})$ and gimeracil $(2.5-25 \mathrm{mg} / \mathrm{kg})$ were administered orally, 5-FU was intravenously injected for 14 consecutive days, and CDDP ( 5 and $7.5 \mathrm{mg} / \mathrm{kg}$ ), was injected on day 1 . The tumors implanted into the righ hind leg of each mouse were directly X-ray irradiated (2-10 Gy) on days 1 and 8 . The tumor volume [1/2 x (the major axis) $\mathrm{x}$ (the minor axis) $\left.{ }^{2}\right]$ was measured twice a week throughout the experiments, and relative tumor volume (RTV) was calculated as follows: $\mathrm{RTV}=$ (mean tumor volume during therapy)/(mean tumor volume at the beginning of the therapy). The antitumor effects of S-1, X-ray and a combination of S-1 and X-ray were estimated using the following equation: mean inhibition rate of tumor growth $(I R, \%)=[1-($ mean RTV of drug-treated group/mean RTV of control group) $\mathrm{x}$ 100].

Western blot analysis. Tumors were homogenized in three volumes of $50 \mathrm{mM}$ Tris- $\mathrm{HCl}(\mathrm{pH} \mathrm{7.6)}$ containing $5 \mathrm{mM}$ $\mathrm{MgCl}_{2}, 25 \mathrm{mM} \mathrm{KCl}$ and $10 \mathrm{mM}$ 2-mercaptoethanol followed by ultra-sonication for $5 \mathrm{~min}$ at $4^{\circ} \mathrm{C}$. The homogenates were centrifuged at $105,000 \times \mathrm{g}$ for $60 \mathrm{~min}$, and aliquots of the supernatant were subjected to Western blot analysis. The supernatant was heated for $2 \mathrm{~min}$ in a boiling water bath and loaded on $12.5 \%$ polyacrylamide gels. After electrophoresis, the proteins were electrically transferred to PVDF membranes at $4^{\circ} \mathrm{C}$. The proteins were immunochemically detected using the Avidin-Biotin-Complex (ABC) method. Anti-human $\gamma$-H2AX and anti-human $B$-actin antibodies were used as primary antibodies, and anti-rabbit IgG was used as a secondary antibody.

Statistical analysis. The significance of differences between groups with or without treatment was assessed using Dunnett's test and the Student's t-test. 
Table I. Antitumor activity and toxicity of S-1, X-ray, and their combination on human non-small cell lung cancer xenografts in mice.

\begin{tabular}{|c|c|c|c|c|c|c|c|}
\hline \multirow[b]{2}{*}{ Group } & \multicolumn{2}{|c|}{ Doses } & \multirow[b]{2}{*}{$\mathrm{N}$} & \multicolumn{2}{|c|}{ Mean IR (\%) } & \multicolumn{2}{|c|}{ Body weight changes $(\%)$} \\
\hline & $\mathrm{mg} / \mathrm{kg}$ & Gy & & day 15 & day 29 & day 15 & day 29 \\
\hline \multicolumn{8}{|c|}{ Lu-99 tumors } \\
\hline Control & - & - & 6 & - & - & 10.8 & 13.1 \\
\hline S-1 & 8.3 & - & 6 & 42.7 & 46.9 & 2.8 & 11.1 \\
\hline \multirow[t]{3}{*}{ X-ray } & - & 2 & 6 & 17.6 & 23.4 & 13.4 & 14.1 \\
\hline & - & 5 & 6 & 45.4 & 62.1 & 8.2 & 13.5 \\
\hline & - & 10 & 6 & 45.8 & 75.9 & 9.1 & 10.2 \\
\hline \multirow[t]{3}{*}{ S-1/X-ray } & 8.3 & 2 & 6 & $51.5^{\mathrm{a}}$ & $66.1^{\mathrm{a}}$ & 4.4 & 9.9 \\
\hline & 8.3 & 5 & 6 & 51.5 & 69.1 & 3.8 & 9.9 \\
\hline & 8.3 & 10 & 6 & 61.8 & 80.6 & 3.5 & 9.1 \\
\hline \multicolumn{8}{|c|}{ LC-11 tumors } \\
\hline Control & - & - & 6 & - & - & 10.8 & 17.6 \\
\hline S-1 & 8.3 & - & 6 & 25.9 & 27.9 & 9.5 & 14.8 \\
\hline \multirow[t]{2}{*}{ X-ray } & - & 2 & 6 & 19.1 & 23.2 & 12.4 & 18.8 \\
\hline & - & 5 & 6 & 47.5 & 67.6 & 10.2 & 15.1 \\
\hline \multirow[t]{2}{*}{ S-1/X-ray } & 8.3 & 2 & 6 & $60.3^{\mathrm{a}}$ & $67.8^{\mathrm{a}}$ & 8.7 & 16.9 \\
\hline & 8.3 & 5 & 6 & 56.5 & 69.8 & 4.2 & 13.5 \\
\hline
\end{tabular}

S-1 $(8.3 \mathrm{mg} / \mathrm{kg})$ was orally administered once daily for 14 days, and X-ray (2, 5 and $10 \mathrm{~Gy})$ was irradiated on day 1 and 8 . Mean IR (inhibition rate of tumor growth, \%) was calculated on day 15 and 29. ${ }^{*} \mathrm{p}<0.05$, significantly different from both S-1 alone and 2 Gy X-ray alone by IUT-test.

\section{Results}

Antitumor potency of chemoradiotherapy with S-1 against NSCLC xenografts. To determine an optimal dose for combination chemoradiotherapy, we evaluated the antitumor activities of S-1, radiation or a combination of S-1 and radiation on Lu-99 and LC-11 tumors. The minimal toxic dose of S-1 was defined to $8.3 \mathrm{mg} / \mathrm{kg}$ in 14 day-treatment periods; this dose resulted in a decrease in body weight of $<10 \%$ from the initial weight. For radiotherapy, mice were treated with 2, 5 or 10 Gy X-ray irradiation to determine the maximum effect of X-ray alone and define a suitable dose for combination treatment with S-1. As shown in Table I, S-1 treatment resulted in $42-47 \%$ and $25-28 \%$ inhibition of growth of Lu-99 and LC-11 tumors, respectively. X-ray irradiation showed dose-dependent antitumor activity in the range of 2-5 Gy, but 10 Gy irradiation did not result in a further increase in efficacy. Throughout two antitumor experiments, the combination of $\mathrm{S}-1(8.3 \mathrm{mg} / \mathrm{kg})$ with 2 Gy X-ray irradiation resulted in significantly higher antitumor activity than treatment with S-1 alone or 2 Gy X-ray irradiation alone $(\mathrm{p}<0.05)$.

Comparison of $S-1 / X$-ray therapy with UFT/X-ray therapy in NSCLC xenografts. Because chemoradiotherapy with UFT and CDDP is used to treat locally advanced NSCLC patients in Japan (15), we compared the antitumor activities of UFT $(17.5 \mathrm{mg} / \mathrm{kg})$ and $\mathrm{S}-1(8.8 \mathrm{mg} / \mathrm{kg})$, alone and in combination with radiation. Both drugs have similar antitumor efficacy against LC-11 tumors (Fig. 1). However, when combined with 2 Gy irradiation, S- 1 significantly augmented $(\mathrm{p}<0.05)$ the antitumor activity of radiation therapy against LC-11 tumors, and its potency was similar to that of 5 Gy X-ray irradiation alone; however, combination of UFT with 2 Gy $\mathrm{X}$-ray irradiation did not enhance the antitumor activity of radiation therapy (Fig. 1).

Antitumor activity of chemoradiotherapy with CDDP against NSCLC. Using the same tumor (LC-11) xenograft model, we compared the anticancer effect of combination treatment with X-ray irradiation ( 2 Gy x 2) and 5 or $7.5 \mathrm{mg} / \mathrm{kg}$ CDDP (weekly $x$ 2) to that of chemoradiotherapy with S-1. Treatment with 5 and $7.5 \mathrm{mg} / \mathrm{kg}$ CDDP resulted in $40-45 \%$ and $55-60 \%$ inhibition of tumor growth, respectively, and 2 Gy X-ray irradiation resulted in $\sim 35 \%$ inhibition of tumor growth. The antitumor activity of combination treatment with CDDP and X-ray irradiation was not significantly different from the antitumor activities of CDDP alone and/or X-ray irradiation alone (Fig. 2).

Comparison of $S$ - $1 / X$-ray therapy with 5-FU/X-ray therapy in pancreatic cancer xenografts. Chemoradiotherapy with 5-FU is one treatment strategy for patients with locally advanced pancreatic cancer (13). To compare chemoradiotherapy with S-1 to that with 5-FU, the same treatment protocol was performed using oral S-1 $(8.3 \mathrm{mg} / \mathrm{kg})$ and i.v. 5-FU $(15 \mathrm{mg} / \mathrm{kg})$. 


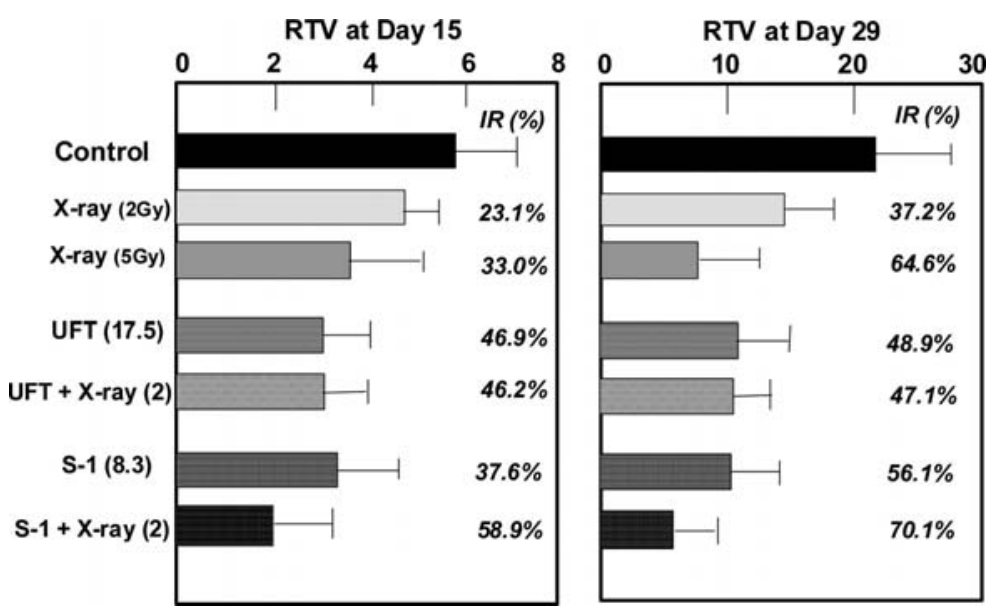

Figure 1. Antitumor effects of combined treatment with X-ray irradiation and oral 5-FU prodrug, S-1 or UFT on LC-11 xenografts in mice. Mice bearing LC-11 tumors in the right foot were treated orally with S-1 $(8.3 \mathrm{mg} / \mathrm{kg})$ or UFT $(17.5 \mathrm{mg} / \mathrm{kg})$ once daily for 14 days, and mice were irradiated with 2 or 5 Gy X-ray irradiation on days 1 and 8 . After treatment, tumor volume was measured on days 15 and 29. "\#Significantly different ( $<<0.05)$ from $\mathrm{S}-1$ group and X-ray irradiation (2 Gy) group by Student's t-test.
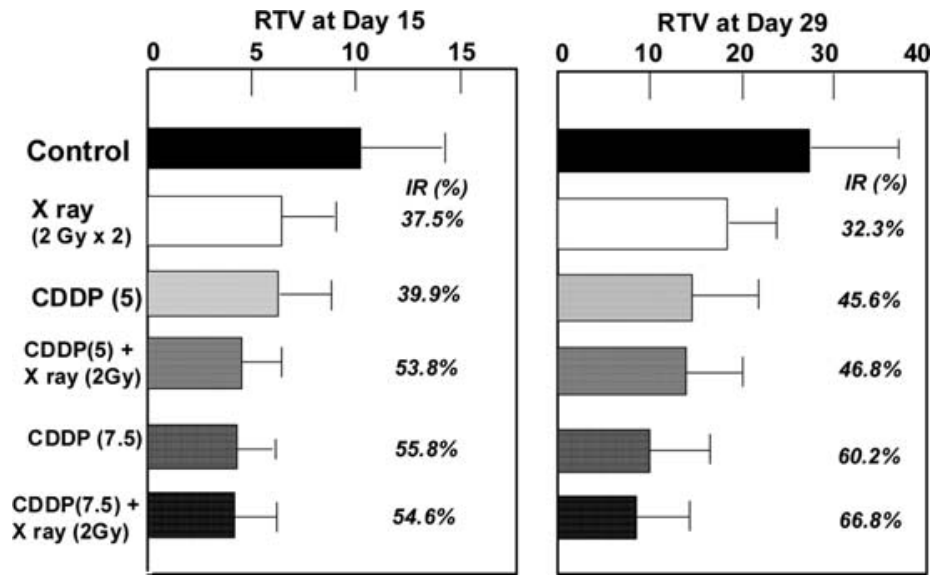

Figure 2. Antitumor effect of the combination of X-ray irradiation with CDDP on human non-small cell lung cancer LC-11 xenografts in mice. The right hind leg of each mouse was irradiated with 2 Gy of X-ray on days 1 and 8 , and CDDP $(5$ or $7.5 \mathrm{mg} / \mathrm{kg})$ was intravenously administered on day 1 . Tumor volume in the right foot of each mouse was measured on days 15 and 29, and the relative tumor volume (RTV) and the inhibition rate (IR) of tumor growth were calculated.

Both treatments resulted in equal toxicity in PAN-4 pancreatic tumor xenografts. As seen in Fig. 3, combination treatment with S-1 and X-ray irradiation resulted in a significant enhancement of antitumor activity $(\mathrm{p}<0.01)$; however, consecutive i.v. administration of 5-FU over a course of 14 days in combination with X-ray irradiation failed to enhance antitumor efficacy, suggesting that in addition to 5-FU, one of the components of S-1 may contribute to radiosensitivity.

Gimeracil-mediated radiosensitization to X-ray irradiation in vivo. To investigate whether gimeracil, a component of S-1, contributes to radiosensitivity, LC-11 tumor xenografts were treated with a combination of gimeracil and 2 or 5 Gy $\mathrm{X}$-ray irradiation in vivo. Gimeracil was administered at a dose of $2.5 \mathrm{mg} / \mathrm{kg}$, which is equivalent to the dose contained in $8.3 \mathrm{mg} / \mathrm{kg} \mathrm{S}-1$, or a 10 -fold higher dose $(25 \mathrm{mg} / \mathrm{kg})$, and neither dose resulted in antitumor activity when used alone; however, combination of gimeracil with 2 Gy X-ray irradiation resulted in a dose-dependent enhancement of the efficacy of X-ray irradiation. The antitumor efficacy of combined treatment with gimeracil $(25 \mathrm{mg} / \mathrm{kg})$ and $2 \mathrm{~Gy}$ $\mathrm{X}$-ray was nearly equivalent to that of $5 \mathrm{~Gy} \mathrm{X}$-ray irradiation as shown in Fig. 4. Similarly, we evaluated the sensitizing effect of $50 \mathrm{mg} / \mathrm{kg}$ of gimeracil in combination with 2 or 5 Gy X-ray irradiation against $\mathrm{KB} / 3$ head and neck cancer xenografts in mice (Fig. 5). Similar to the results in the LC-11 tumor xenograft model, gimeracil significantly $(\mathrm{p}<0.01)$ potentiated the antitumor effect of 2 Gy X-ray irradiation against KB/3 tumor xenografts.

Effect of gimeracil on expression of DNA repair protein. The effect of gimeracil administration on repair of radiationinduced DNA damage was determined in LC-11 tumor xenografts. Tumor-bearing mice were X-ray irradiated (2 Gy) and administered $25 \mathrm{mg} / \mathrm{kg}$ gimeracil. Oral gimeracil treatment was continued for two days. On days 1 and 3, tumors were resected, and the expression of $\gamma-\mathrm{H} 2 \mathrm{AX}$ protein in tumors was assessed. As shown in Fig. 6, the expression of $\gamma$-H2AX in LC-11 tumors increased $24 \mathrm{~h}$ after irradiation and then decreased by day 3; however, accumulation of $\gamma$-H2AX 

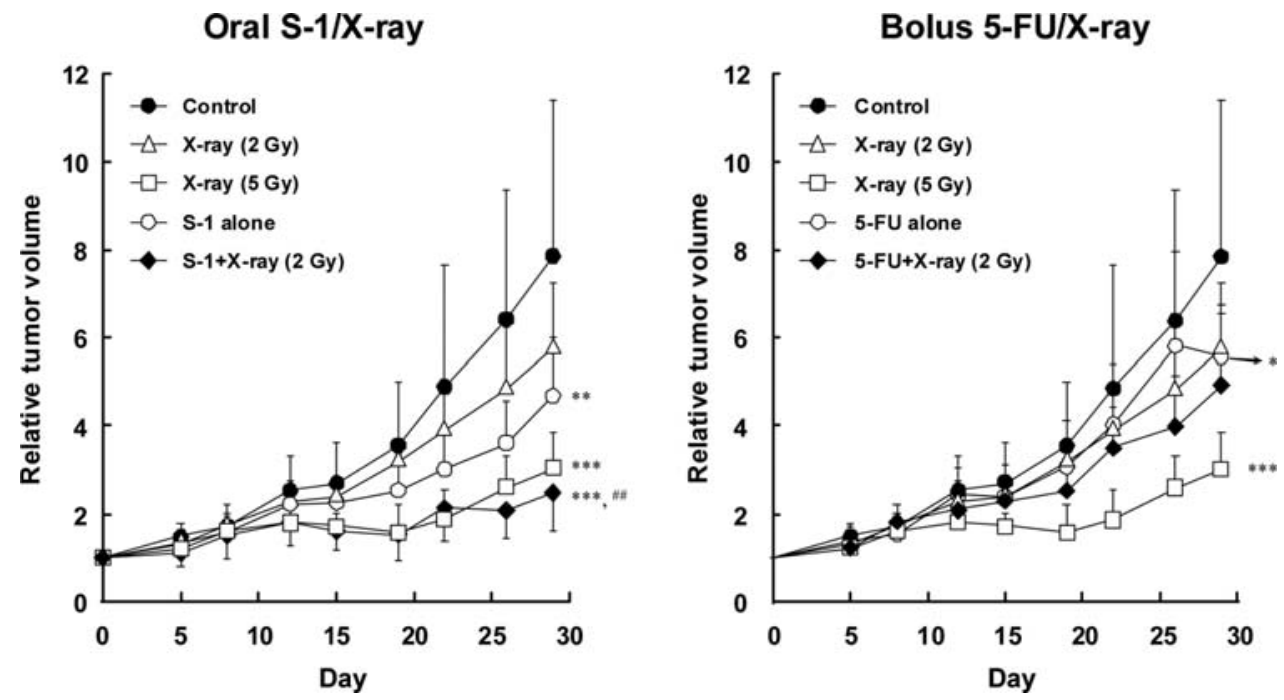

Figure 3. Combined effect of X-ray irradiation and oral S-1 or bolus 5-FU against human pancreatic cancer PAN-4 xenografts in mice. Mice were X-ray irradiated (2 and $5 \mathrm{~Gy}$ ) on days 1 and 8 and treated with oral S-1 (8.3 mg/kg) or intravenous 5 -FU (15 mg/kg) consecutively for 14 days alone or in combination with weekly X-ray irradiation $(2 \mathrm{~Gy}) .{ }^{*}{ }^{* *},{ }^{* * *}$ Significantly different $(\mathrm{p}<0.05, \mathrm{p}<0.01$ and $\mathrm{p}<0.001$, respectively) from control group by Dunnett's

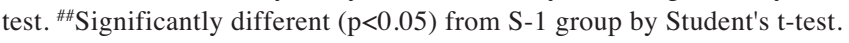

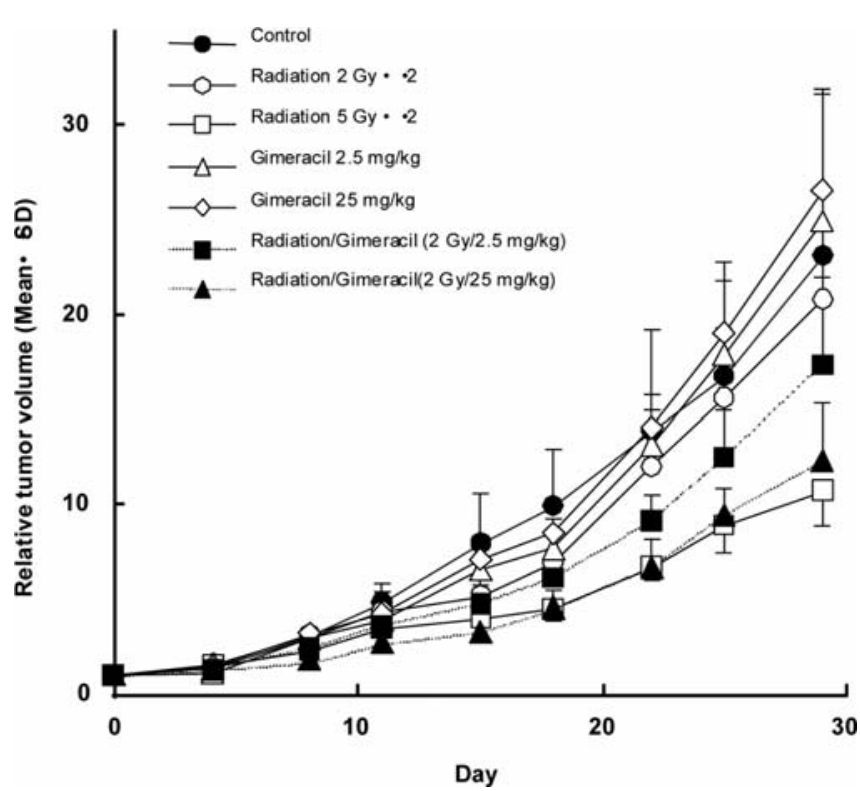

Figure 4. Effect of gimeracil on antitumor activity of $\mathrm{X}$-ray irradiation against LC-11 non-small cell lung cancer xenografts. LC-11-bearing mice were X-ray irradiated ( 2 or $5 \mathrm{~Gy}$ ) on days 1 and 8 during the therapeutic periods, and gimeracil ( 2.5 and $25 \mathrm{mg} / \mathrm{kg})$ was orally administered for 14 days alone or in combination with $\mathrm{X}$-ray irradiation. ${ }^{*, * *}$ Significantly different $(\mathrm{p}<0.05, \mathrm{p}<0.01$, respectively) from control group by Dunnett's test. "Nignificantly different $(\mathrm{p}<0.01)$ from $\mathrm{X}$-ray irradiation $(2 \mathrm{~Gy})$ group by Student's t-test.

proteins was markedly decreased in tumors treated with gimeracil, suggesting that gimeracil may inhibit the rapid repair of X-ray-induced DNA damage in tumors.

\section{Discussion}

Chemoradiotherapy with cytotoxic drugs is the most widely available therapeutic method to treat locally advanced cancers and is used to treat patients with head and neck, lung and GI cancers. In chemoradiotherapy, cytotoxic drugs including 5-FU and CDDP are concomitantly combined with fractionated radiotherapy; however, 5-FU has not been used to treat NSCLC patients because it has low clinical activity against this type of cancer.

The present study was initiated to clarify whether S-1, a unique oral 5-FU formulation, enhances the antitumor efficacy of X-ray irradiation against human NSCLC and pancreatic cancers, which are difficult to treat. Combination of the minimum toxic dose of S-1 with two weekly 2 Gy $\mathrm{X}$-ray irradiation treatments resulted in significantly $(\mathrm{p}<0.05)$ higher antitumor activity against NSCLC xenografts (Lu-99 and LC-11) than either treatment alone (Table I). Because UFT (a 5-FU prodrug consisting of tegafur and uracil) is used to treat patients with locally advanced NSCLC in combination with radiation in Japan (15), we compared the antitumor potencies of S-1 and UFT combined with $\mathrm{X}$-ray irradiation against LC-11 tumor xenografts in vivo. Treatment with either $8.3 \mathrm{mg} / \mathrm{kg} \mathrm{S}-1$ or $17.5 \mathrm{mg} / \mathrm{kg}$ UFT resulted in similar antitumor activities; however, S-1 treatment resulted in higher antitumor activity than UFT treatment in combination with 2 Gy X-ray irradiation. These results suggest that a component of S-1 different from UFT contributes to sensitization to radiation.

Because CDDP-based chemotherapy is frequently employed in chemoradiotherapy to treat NSCLC patients, the combined activity of CDDP ( 5 and $7.5 \mathrm{mg} / \mathrm{kg}$ ) with $2 \mathrm{~Gy}$ $\mathrm{X}$-ray irradiation was assessed. Combined CDDP and X-ray irradiation treatment resulted in little enhancement of tumorinhibitory activity against LC-11 tumor xenografts. Unlike the radiation dosing schedules used in clinical practice, weekly and twice weekly schedules of X-ray irradiation were employed in this study to avoid damage in tumor-bearing mice due to frequent X-ray treatment; therefore, it would likely be difficult to observe an obvious sensitizing effect of CDDP to X-ray irradiation. 


\section{Day 15}

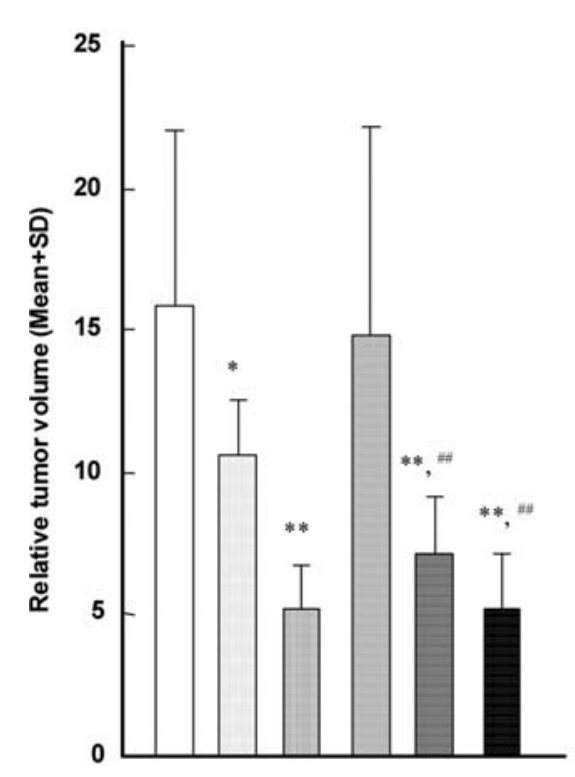

Day 29

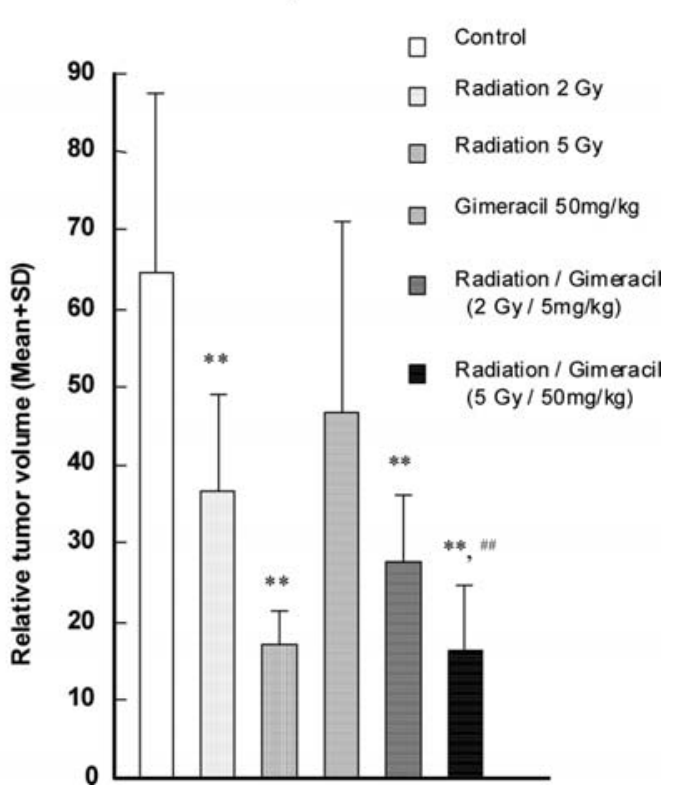

Figure 5. Effect of gimeracil on antitumor activity of X-ray irradiation against KB/C3 head and neck cancer xenografts. KB/C3-bearing mice were X-ray irradiated ( 2 or 5 Gy) on days 1 and 8 , and gimeracil was orally administered for 14 days alone or in combination with X-ray irradiation. On days 15 and 29 , the tumor volume was measured. ${ }^{*}, * *$ Significantly different $(\mathrm{p}<0.05$ and $\mathrm{p}<0.01)$ from control group by Dunnett's test. ${ }^{\# \#}$ Significantly different $(\mathrm{p}<0.01)$ from X-ray irradiation (2 Gy) group by Student's t-test.
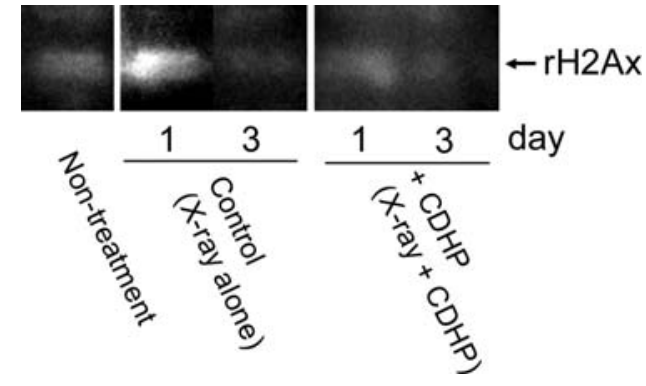

Figure 6. Expression of $\gamma-\mathrm{H} 2 \mathrm{AX}$ (P139) in LC-11 tumor-bearing mice treated with $\mathrm{X}$-ray irradiation alone or in combination with oral gimeracil. Mice were treated once with 2 Gy X-ray irradiation, and 24 h later, gimeracil or saline control was administered for 3 days. LC-11 tumors were surgically removed on days 1 and 3 , and expression of $\gamma-\mathrm{H} 2 \mathrm{AX}$ was detected by immunoblotting.

We further compared the efficacy of S-1/X-ray therapy to that of 5-FU/X-ray therapy against PAN-4 pancreatic tumors by using the common minimum toxic doses of both drugs, and found that the combination of $\mathrm{S}-1(8.3 \mathrm{mg} / \mathrm{kg})$ with $\mathrm{X}$-ray irradiation $(2 \mathrm{~Gy})$ resulted in higher efficacy than the combination of i.v. 5-FU $(15 \mathrm{mg} / \mathrm{kg})$ with X-ray irradiation (2 Gy), suggesting that a component of S-1 contributed to radiosensitization (Fig. 3).

Gimeracil, a component of S-1, is an inhibitor of DPD and strongly inhibits the degradation of 5-FU as well as the catabolism of the natural pyrimidine uracil in the liver and tumors; therefore, elevated concentrations of natural pyrimidine may affect the antitumor activity of radiation. Although large amounts of uracil (100-200 mg/kg) were administered consecutively in combination with 2 Gy X-ray irradiation, no difference was detected in the anti-tumor activity of radiation with or without uracil (data not shown). As shown in Figs. 4 and 5, treatment with gimeracil, which showed no anticancer activity on its own, enhanced the antitumor activity of X-ray irradiation against two tumor xenograft model (LC-11 and PAN-4) in a dose-dependent manner, suggesting that in addition to the cytotoxic function of 5-FU or CDDP, gimeracil may contribute to sensitization to radiotherapy. The detailed functional mechanism by which gimeracil enhances the antitumor effects of X-ray irradiation remains unclear, but our preliminary results as shown in Fig. 6 suggest that gimeracil may directly or indirectly inhibit the repair of radiation-induced DNA damage in tumors. Further in vitro and in vivo studies are necessary to investigate the inhibition of DNA repair by gimeracil during radiotherapy.

Although the effects of various inhibitors of DNA repair, such as poly (ADP-ribose) polymerase and related enzymes have been studied in vitro (28-30), there are currently no clinically available radiosensitizing drugs. Accordingly, gimeracil, which is in clinical use for the treatment of cancer as a component of S-1, may be considered a valuable therapeutic agent due to its ability to sensitize tumors to radiation.

Throughout the in vivo experiments described in this study, the advantages of chemoradiotherapy with S-1 over chemoradiotherapy with 5-FU and its prodrugs should be noted. Treatment with gimeracil results in inhibition of repair of radiation-induced DNA damage in addition to direct enhancement by anticancer drugs of the initial radiation damage by their incorporation into DNA, inhibition by cytotoxic drugs of cellular repair, accumulation of tumor cells in a radiosensitive phase or elimination of radioresistant phase cells due to treatment with anticancer drugs, elimination of 
hypoxic cells after drug treatment, and inhibition by anticancer drugs of the accelerated repopulation of tumor cells (31).

\section{References}

1. Tannock IF: Treatment of cancer with radiation and drugs. J Clin Oncol 14: 3156-3174, 1996.

2. Vokes EE and Weichselbaum RR: Concomitant chemoradiotherapy: rationale and clinical experience in patients with solid tumors. J Clin Oncol 8: 911-934, 1990.

3. Belka C, Nieder C and Molls M: Biological basis of combine radio- and chemotherapy. In: Multimodal Concepts for Cytotoxic Drugs and Radiation Therapy. Brown JM, Metha MP and Mieder C (eds). Springer, Berlin, pp3-17, 2006.

4. Milas L, Mason KA, Liao Z and Ang KK: Chemoradiotherapy: emerging treatment improvement strategies. Head Neck 25: $152-167,2003$

5. Herskovic A, Martz K, Al-Sarraf M, Leichman L, Brindle J, Vaitkevicius V, Cooper V, Byhardt R, Davis L and Emami B: Combined chemotherapy and radiotherapy compared with radiotherapy alone. New Eng J Med 326: 1593-1598, 1992.

6. Brizel DM, Albers ME, Fisher SR, Scher RL, Richtsmeiner WJ, Hars V, George SL, Huang AT and Prosnitz LR: Hyperfractionated irradiation with or without concurrent radiotherapy for locally advanced head and neck cancer. New Eng J Med 338: 1798-1804, 1998.

7. Furuse K, Fukuoka M and Kawahara M: Phase III study of concurrent versus sequential thoracic radiotherapy in combination with mitomycin, vindesine, and cisplatin in unresectable stage III non-small-cell lung cancer. J Clin Oncol 17: 2692-2699, 1999.

8. Morris M, Eifel PJ, Lu J, Grigsby PW, Levenback C, Stevens RE, Rotman M, Gershenson DM and Mutch DG: Pelvic radiation with concurrent chemotherapy compared with pelvic and paraaortic radiation for high-risk cervical cancer. New Eng J Med 340: 1137-1143, 1999.

9. Rich TA, Shepard RC and Mosley ST: Four decades of continuing innovation with fluorouracil: current and future approaches to fluorouracil chemoradiation therapy. J Clin Oncol 22: 2214-2232, 2004.

10. Wendt TG, Grabenbauer GG, Rodel CM, Thiel HJ, Aydin H, Rohloff R, Wustrow TP, Iro H, Popella C and Schalhorn A: Simultaneous radiochemothrapy versus radiotherapy alone in advanced head and neck cancer: a randomized multicenter study. J Clin Oncol 16: 1318-1324, 1998.

11. Al-Sarraf M, Martz K, Herskovic A, Leichman L, Brindle JS, Vaitkevicius VK, Cooper J, Byhardt R, Davis L and Emami B: Progress report of combined chemoradiotherapy versus radiotherapy alone in patients with esophargeal cancer: an intergroup study. J Clin Oncol 15: 277-284, 1997.

12. Walsh TN, Nooman N, Hollywood D, Kelly A, Keeling N and Hennessy TPJ: A comparison of multimodal therapy and surgery for esophargeal adenocarcinoma. New Eng J Med 335: 462-467, 1996.

13. Moertel CG, Frytak S, Hahn RG, O'Connell MJ, Reitemeier RJ, Rubin J, Schutt AJ, Weiland LH, Childs DS, Holbrook MA, Lavin PT, Livstone E, Spiro H, Knowlton A, Kalser M, Barkin J, Lessner H, Mann-Kaplan R, Ramming K, Douglas HO Jr, Thomas P, Nave H, Bateman J, Lokich J, Brooks J, Chaffey J, Corson JM, Zamcheck N and Novak JW: Therapy of locally unresectable pancreatic carcinoma: a randomized comparison of high dose (6000 rads) radiation alone, moderate dose radiation (4000 rads + 5-fluorouracil), and high dose radiation + 5fluorouracil: the Gastrointestinal Tumor Study Group. Cancer 56: 2563-2568, 1981.

14. Kato H, Ichinose Y, Ohta M, Hata E, Tsubota N, Tada H, Watanabe Y, Wada H, Tsuboi M, Hamajima N, Ohta M and Japan Lung Cancer Research Group on Postsurgical Adjuvant Chemotherapy: A randomized trial of adjuvant chemotherapy with uracil-tegafur for adenocarcinoma of the lung. New Eng J Med 350: 1713-1721, 2004.

15. Ichinose $Y$, Nakai Y, Kudoh S, Senba H, Yoshida S, Nukiwa T, Yamamoto H, Yamane Y, Niitani H and UP-RT Study Group: Uracil/tegafur plus cisplatin with concurrent radiotherapy for locally advanced non-small cell lung cancer: a multi-institutional phase II trial. Clin Cancer Res 10: 4369-4373, 2004.
16. Shirasaka T, Shimamoto Y, Ohshimo H, Yamaguchi M, Kato T, Yonekura K and Fukushima M: Development of a novel form of an oral 5-fluorouracil derivative (S-1) directed to the potentiation of the tumor selective cytotoxicity of 5-fluorouracil by two biochemical modulators. Anticancer Drugs 7: 548-557, 1996.

17. Shirasaka T, Nakano K, Takechi T, Satake H, Uchida J, Fujioka A, Saito H, Okabe H, Oyama K, Takeda S, Unemi N and Fukushima $\mathrm{M}$ : Antitumor activity on $1 \mathrm{M}$ tegafur-0.4 M 5-chloro-2,4-dihydroxypyridine-1 M potassium oxonate (S-1) against human colon carcinoma orthotopically implanted into nude rats. Cancer Res 56: 2602-2606, 1996.

18. Kawahara M, Furuse K, Segawa Y, Yoshimori K, Matsui K, Kudoh S, Hasegawa K, Niitani H and S-1 Cooperative Study Group (Lung Cancer Working Group): Phase II study of S-1, a novel oral fluorouracil, in advanced non-small cell lung cancer. Br J Cancer 85: 939-943, 2001.

19. Ichinose Y, Yoshimori K, Sakai H, Nakai Y, Sugiura T, Kawahara $M$ and Niitani H: S-1 plus cisplatin combination chemotherapy inpatients with advanced non-small cell lung cancer: a multi-institutional phase II trial. Clin Cancer Res 10: 7860-7864, 2004.

20. Okusaka T, Funakoshi A, Furuse J, Boku N, Yamao K, Ohkawa S and Saito H: A late phase II study of S-1 for metastatic pancreatic cancer. Cancer Chemother Pharmacol 61: 615-621, 2008

21. Nakamura K, Yamaguchi T, Ishihara T, Sudo K, Kato H and Saisho H: Phase II trial of oral S-1 combined with gemcitabine in metastatic pancreatic cancer. Br J Cancer 94: 1575-1579, 2006.

22. Harada K, Kawaguchi S, Supriatno, Onoue T, Yoshida H and Sato M: Combined effects of the oral fluoropyrimidine anti-cancer agent, S-1 and radiation on human oral cancer cells. Oral Oncol 40: 713-719, 2004.

23. Harada K, Kawaguchi S, Supriatno, Kawashima Y, Yoshida H and Sato M: S-1, an oral fluoropyrimidine anti-cancer agent, enhanced radiosensitivity in a human oral cancer cell line in vivo and in vitro: involvement possibility of inhibition of survival signal, Akt/PKB. Cancer Lett 226: 161-168, 2005.

24. Nakata E, Fukushima M, Takai Y, Nemoto K, Ogawa Y, Nomiya T, Nakamura Y, Milas L and Yamada S: S-1, an oral fluoropyrimidine, enhances radiation response of DLD-1/FU human colon cancer xenografts resistant to 5-FU. Oncol Rep 16: 465-471, 2006.

25. Zeng L, Ou G, Itasaka S, Harada H, Xie X, Shibuya K, KizakaKondoh S, Morinibu A, Shinomiya K and Hiraoka M: TS-1 enhances the effect of radiotherapy by suppressing radiationinduced hypoxia-inducible factor-1 activation and inducing endothelial cell apoptosis. Cancer Sci 99: 2327-2335, 2008.

26. Kim HM, Bang S, Park JY, Seong J, Song SY, Cheng JB and Park SW: Phase II trial of S-1 and concurrent radiotherapy in patients with locally advanced pancreatic cancer. Cancer Chemother Pharmacol 63: 535-541, 2009.

27. Tsukuda M, Ishitoya J, Mikami Y, Matsuda C, Horiuchi C, Taguchi T, Satake K, Kawano T, Takahashi M, Nishimura G, Kawakami M, Sakuma Y, Watanabe M, Shiono O, Komatsu M and Yamashita Y: Analysis of feasibility and toxicity of concurrent chemoradiotherapy with S-1 for locally advanced squamous cell carcinoma of the head and neck in elderly cases and/or cases with comorbidity. Cancer Chemother Pharmacol 64: 945-952, 2009.

28. Suto MJ, Turner WR, Arundel-Suto CM, Werbel LM and Sebolt-Leopold JS: Dihydroisoquinolines: the design and synthesis of a new series of potent inhibitors of poly(ADPribose) polymerase. Anticancer Drug Des 7: 107-117, 1991.

29. Banasik M, Komura H, Shimoyama M and Ueda K: Specific inhibitors of poly(ADP-ribose) synthetase and mono(ADPribosyl) transferase. J Biol Chem 267: 1569-1575, 1992.

30. Griffin RJ, Pemberton LC, Rhodes D, Bleasdale C, Bowman K, Calvert AH, Curtin NJ, Durkacz BW, Newell DR and Porteous JK: Novel potent inhibitors of the DNA repair enzyme poly(ADP-ribose) polymerase (PARP). Anticancer Drug Des 10: 507-514, 1995.

31. Nishimura Y: Rationale for chemoradiotherapy. Int J Clin Oncol 9: 414-420, 2004. 